\title{
Nursing and Health Care
}

\section{EKG Sensor Pad Innovation and Strategy}

Cheryl Ann Alexander ${ }^{*}$ and Lidong Wang ${ }^{2}$

\section{Affiliation}

${ }^{1}$ Institute for IT innovation and Smart Health, Mississippi, USA

${ }^{2}$ Institute for Systems Engineering Research, Mississippi State University, Vicksburg, USA

*Corresponding author: Cheryl Ann Alexander, Institute for IT Innovation and Smart Health, Mississippi, USA, Email:

cheryl@techhealthsolutions.org

Citation: Alexander AC and Wang L. EKG sensor pad innovation and strategy (2019) Nursing and Health Care 4: 50-52.

Received: Oct 05, 2019

Accepted: Oct 23, 2019

Published: Oct 28, 2019

Copyright: (C) 2019 Alexander AC, et al., This is an open-access article distributed under the terms of the Creative Commons Attribution

License, which permits unrestricted use, distribution, and reproduction in any medium, provided the original author and source are credited

\begin{abstract} reason that this study was done.

Keywords: Innovation, Wearable, Wireless sensor, Arrhythmias.

Abbreviations: NPD-New Product Development, CS-Compression System

\section{Introduction}

Innovation is a key toward success and winning over competition in the market. Not only are new ideas brought about systematically, but also improvements to old ideas. Effective management is required to manage innovation and attract new customers. For gaining a new perspective and advantage over innovations, it is important to have a widespread understanding of the product and the selling nature. Product innovation management will be much more effective if administration assigns a team to handle this process. It is also helpful to managers to help identify, analyze, and understand strengths and weaknesses [1]. An executive summary is the first step in this process.
\end{abstract}

Innovation is the key to having a competitive edge in the market. Success comes from not just new ideas, but improvements to old ideas, and attracting new customers with new innovations. Innovations should make the product stand out to the consumer. There are challenges and barriers to innovations in the market. Innovations may be more expensive; therefore, it may be less challenging to simply edit. Wearable sensors have a strong potential for success in the market. Because this is the first sign of heart attack, this is an easy and predictable method as to identifying heart arrhythmias. The purpose of this review is to determine if wearable sensors are effective at notifying the patient and providers of cardiac problems prior to an event. Many patients are not very confident in the applications of new technologies such as wearable sensors. This is a main

Consumer expectations are more important than technology when implementing a new product, whether global or continental. Innovative products require several design elements which make the product stand out to consumers. Because technology is moving quickly, companies must keep developing new items quickly. But these items must appeal to the consumer, be cost-effective, and upgrade technology [2]. That makes quality function deployment very important as this process will help managers maximize customer satisfaction. Each customer requirement satisfaction response is measured using a mathematical programming method. Fuzzy sets are used frequently to measure input and output datasets based on minimal technical difficulty, maximum customer satisfaction, and minimum incremental cost [3].

Wearable sensors have a strong potential for innovation in the global market. Already widely used, wearable sensors are used in daily monitoring, well-being management, and rehabilitation in both urban and rural areas. Wearable sensors, specifically sensors which measure the heart rhythm, are extremely valuable in cardiology services for maintaining and diagnosing heart dysrhythmia. This can be helpful in

diagnosing heart attack prior to a myocardial infarction because a dysrhythmia is one of the first silent symptoms of heart attack [4-6]. Figure1 shows the location of potential sensors and the relationship between the wearables and providers, family, and the Internet of Things (IoT).

Citation: Alexander AC and Wang L. EKG sensor pad innovation and strategy (2019) Nursing and Health Care 4: 50-52. 


\begin{tabular}{|c|c|c|}
\hline Technology & Benefits & Healthcare Sectors \\
\hline $\begin{array}{c}\text { Clinical Reminder } \\
\text { Systems }\end{array}$ & $\begin{array}{c}\text { Provide just-in-time } \\
\text { reminders to } \\
\text { clinicians at the point } \\
\text { of care, consistent } \\
\text { with the latest } \\
\text { evidence-based } \\
\text { medicine guidelines }\end{array}$ & $\begin{array}{c}\text { Information/Decision } \\
\text { Support }\end{array}$ \\
\hline $\begin{array}{c}\text { Assist with } \\
\text { Clinical Decision } \\
\text { Support Systems } \\
\text { diagnosing a patient's } \\
\text { condition, drug } \\
\text { dosage, procedures } \\
\text { administering } \\
\text { reminders to patients }\end{array}$ & $\begin{array}{c}\text { Information/Decision } \\
\text { Support }\end{array}$ \\
\hline $\begin{array}{c}\text { Telemedicine } \\
\text { healthcare services } \\
\text { from one location to } \\
\text { another }\end{array}$ & $\begin{array}{c}\text { Information/Decision } \\
\text { Support, }\end{array}$ \\
$\begin{array}{c}\text { Computerized } \\
\text { patient records and } \\
\text { Electronic Medical Technology } \\
\text { Record (EMR) } \\
\text { systems }\end{array}$ & $\begin{array}{c}\text { Digitalize patient } \\
\text { information for } \\
\text { decision support }\end{array}$ & $\begin{array}{c}\text { Information/Decision } \\
\text { Support }\end{array}$ \\
\hline $\begin{array}{c}\text { Wireless Local Area } \\
\text { Network-based } \\
\text { (WLAN) mobile } \\
\text { computing systems, } \\
\text { wearable monitoring } \\
\text { devices }\end{array}$ & $\begin{array}{c}\text { Increase the quality } \\
\text { of patient care, } \\
\text { improve a hospital's } \\
\text { overall operation, and } \\
\text { reduce costs }\end{array}$ & $\begin{array}{c}\text { Information/Decision } \\
\text { Support }\end{array}$ \\
\hline
\end{tabular}

Table 1: Some technologies in healthcare.

\section{Challenges and Barriers to Innovation}

Challenges and barriers exist for implementing new innovations to the market. Creation must exist and start with concept development to reduce market uncertainties. Exploration activities also seek the value extraction from and validation of value propositions [8]. The market is a competitive strategy in a complex pattern of products and services. There are few studies on how to manage Product-Service Strategy (PSS), and prior studies mainly concern the conceptual design. PSS is a complex system of innovation management and for success, strategy, support, and tactics are key [9].

Attractive factors and features lead authors to do extensive research on products like sensors. There are several hierarchal of features, the proposed integrative method, and the fuzzy relationship matrix, which are included in global challenges [2]. Listed below are several global and local challenges $[1,8,9]$ :

- Challenge one - finding concepts that reduce market uncertainty, and transformation of value propositions in products and services.

- Challenge two-produce more value with less environmental impact affecting customer choice.

- Challenge three-failing to handle all the factors involved in product innovation such as stakeholders, functions, activities, product elements, supporting elements, and service elements.

- Challenge four-innovation has been identified as the most elusive factor in organizational processes and outcomes to be quantitatively and qualitatively analyzed.

New Product Development (NPD) should be considered carefully prior to making any plans because NPD is very close to NPD and this needs to be carefully considered when looking at challenges. And because NPD is estranged from NPP, this is called the fuzzy front end of NPD and full of vagueness and imprecision. Because inherent fuzziness, there is some express detail in application related to fuzziness [3].

There are also specific barriers to innovation delivery in other countries. Product innovativeness, new and significantly improved features, and aesthetics can be valued in many countries as necessary for an innovative product. Quality is the primary useful feature looked for in a foreign country when an item is shipped, along with cost $[1,2]$. However, certain barriers and solutions exist which include $[2,8]$ :

- Customer senses and feelings are translated from qualitative information in Japan and India, among other countries.

- Japanese buyers want attractive products and what is attractive to one person may not be to another.

- Varying laws and regulations, tariffs, legislation regarding importation and exports, etc., can affect new product entrepreneurship greatly and must be followed.

- It is also important to strengthen the innovation process based on the context of innovation-based technology. Not all countries have the same laws or rules, stakeholder interests, etc.

\section{Strategies to Overcome Innovation Challenges}

Strategies to overcome these challenges include a variety of actions. There are several cycles in the life of a new product which includes about four theoretical levels. The most critical cycle is transition; this cycle usually lasts approximately 18-36 months. Transition implies the difference between a start-up and a legitimatized business. Transition implies the following: rapid growth and development, acquiring resources, establishing credibility and legitimacy [8].

Sometimes in innovation management, some parts are overlooked; strategic business model design, reliability, and performance evaluation to name a few. Past PSS developments haven't provided a closed loop framework, and most provide only a fraction of the problem. By assessing the whole innovation, there can be better understanding of motives, etc. [9].

Innovations, with the creation of new ideas, help foster knowledge and newer ideas, and enhance business performance. This should be done prior to advancing through sales. Radical and recent needs indicate that innovation needs to grow now; new ideas are mostly filled with challenges and barriers and should be controlled with precision and radical thought [1].

Innovation and new ideas can get caught up with varying tax laws, tariffs, and state/provincial laws. A simple method of dealing with this issue is entrepreneurship technology; gaining influence in the last few years, this is a study of technology and entrepreneurship. However, little attention has been paid to the innovation and entrepreneur relationship. There must be a refinement, adjustment, and attention paid to innovation management. Discuss the regulations required with the organizational leadership and this barrier should be gone [8].

\section{Several Criteria for Innovation: ECG Strategy}

Wearable sensors have a strong potential for innovation in the global market. Already widely used, wearable sensors are used in daily monitoring, well-being management, and rehabilitation in both urban and rural areas. Wearable sensors, specifically sensors which measure the heart rhythm, are extremely valuable in cardiology services for maintaining and diagnosing heart dysrhythmia. This can be helpful in diagnosing heart attack prior to a myocardial infarction because a dysrhythmia is one of the first silent symptoms of heart attack [4-6]. An innovative approach under discussion is about the Electrocardiograph (ECG) sensor. Figure 2 depicts a new type of wearable ECG sensor which may replace many older types of sensors (biomed.net, 2019).

According to Chen, Ko and Yeh, quality is the most important criteria to evaluate prior to sending out an innovation; using a fuzzy numbers algorithm, evaluation is generally carried out in linguistic terms [3]. Another important criterion for evaluation is the strength of battery power. How long it lasts and how strong it is belonging to both global and local areas. Companies want to evaluate how long the battery lasts during continuous ECG monitoring, and this is a high priority [5]. 


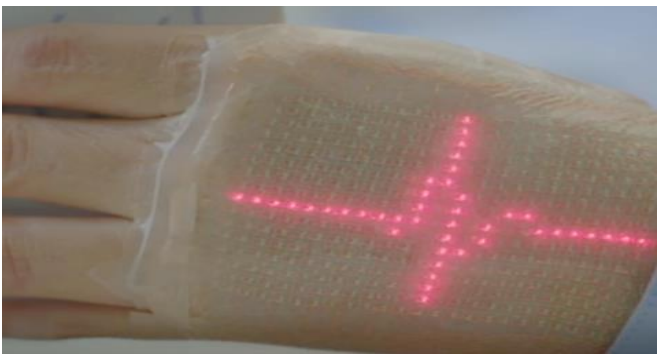

Figure 2: A new type of wearable which may replace older types.

In Compression System (CS) technique, this significantly enhances any criterion which compresses the EKG on the node, allowing reading and transmission with ultralow encoding complexity. Today, sensor wearable garments with transmitters, measuring different various physiological measurements [5]. This criterion is especially important when considering criteria for global deployment [6]. Wearable sensors have compression sensors, so each have a powerful number for biosignal and changes the original signal into other domains [4].

Because globalization and rapid changes with enhanced customer service, most businesses have been paying increasing attention to enhanced customer satisfaction, higher profits, and gaining competitive advantage [1]. Customer satisfaction is important to any business, driving demand, price, all market variables. To lose sight of the vulnerability of a product based on price is ill-advised and can destroy a company [8]

\section{Conclusion}

With the advent of an innovation, there are several responsibilities, and they must be handled. One method of handling challenges which may arise is the technology entrepreneurship area, the product development area, and do not forget customer satisfaction. Sometimes rules and regulations may vary from country to country and rules and regulations vary so being prepared is always a good idea.

Entrepreneur technology is also important because this is a newer method to examine barriers and challenges by looking at technology as an entrepreneurial endeavor. Being prepared for barriers and challenges, having an action plan for each allows the organization to be prepared in advance for trouble and remove any obstacle to an effective global deployment plan. Some barriers to globalization include tariffs, laws, monies to be paid, but other barriers could include attraction for customers, etc. Challenges are like barriers but present only a more expansive problem such as customer wants and needs, produce innovations with more value rather than economic impact, etc.

\section{Acknowledgment}

The authors would like to thank Technology \& Healthcare Solutions and the Institute for IT Innovation and Smart Health for support.

\section{References}

1. Haleem A, Kumar S and Luthra S. Flexible System Approach for Understanding Requisites of Product Innovation Management (2018) Glo J flex Sys Man 19: 19-37. https://doi.org/10.1007/s40171-017-0171-7

2. Kang X, Yang M, Wu Y and Ni B. Integrating Evaluation Grid Method and Fuzzy Quality Function Deployment to New Product Development (2018) Math Prob Eng 1-15. https://doiorg.proxy1.ncu.edu/10.1155/2018/2451470

3. Chen LH, Ko WC and Yeh FT. Approach based on fuzzy goal programing and quality function deployment for new product planning (2017) Euro J Oper Res 259: 654-663. https://doiorg.proxy1.ncu.edu/10.1016/j.ejor.2016.10.028

4.--Huang H, Hu S and Sun Y. Energy-efficient ECG compression in wearable body sensor network by leveraging empirical mode decomposition (2018) IEEE EMBS International Conference on Biomedical \& Health Informatics (BHI), United States, pp. 1-4. https://doi.org/10.1109/BHI.2018.8333391

5. Zhang J, Yu LZ, Gu Z, Li Y and Lin Z. Multichannel Electrocardiogram Reconstruction in Wireless Body Sensor Networks Through Weighted \$lell $\{1,2\} \$$ Minimization (2018) Instrum Meas 9: 2024-2034. https://doi.org/10.1109/TIM.2018.2811438

6. Rapin, M. Wearable Sensors for Frequency-Multiplexed EIT and Multilead ECG Data Acquisition (2019) Biomed Eng 3: 810

https://doiorg.proxy1.ncu.edu/10.1109/TBME.2018.2857199

7. Daim TU, Tarman RT and Basoglu N. Exploring barriers to innovation diffusion in health care service organizations: An issue for effective integration of service architecture and information technologies (2008) In Proceedings of the 41st Annual Hawaii International Conference on System Sciences (HICSS 2008), United States, pp. 7-10. https://doi.org/10.1109/HICSS.2008.159

8. Souza M, Filho LDM, Bagno RB, Souza WC and Cheng LC. A Process Model Integrated to Innovation Management Tools to Support Technology Entrepreneurship (2018) Portland International Conference on Management of Engineering and Technology (PICMET), United States. https://doirg.proxy1.ncu.edu/10,23919/PICMET.2018.8481921

9. Song W, Ming X, Han Y, Xu Z and Wu Z. An integrative framework for innovation management of product-service system (2015) Int J Production Res 53: 2252-2268. https://doiorg.proxy1.ncu.edu/10.1080/00207543.2014.932929

ECG sensors are just one innovation capable for global impact. Several plans for implementation can include looking at the market, improving battery power, determining exactly is necessary for globalization. With a combination of preparing for challenges and barriers, looking for new innovations such as the ECG sensors, organizations can prepare securely for entry into the global market. 